\title{
Metallo-celluloses, 2 Synthesis of cellulose derivatives bearing lateral bis-terpyridine ruthenium(II) complexes
}

\author{
Bettina Laube, Oliver Schmelz, Matthias Rehahn *, Winfried Wunderlich
}

Ernst-Berl-Institute for Chemical Engineering and Macromolecular Science, Darmstadt University of Technology, Petersenstr. 22, 64287 Darmstadt, Germany; Fax +49 (0)6151/ 16 4670; mrehahn@dki.tu-darmstadt.de

(Received: September 23, 2003; published: December 10, 2003)

\begin{abstract}
An efficient method is described for the simultaneous introduction of 4'-p-benzyl-2,2':6',2"-terpyridine and benzyl side groups into cellulose. For this purpose, cellulose triacetate was treated in dimethyl sulfoxide/ $\mathrm{NaOH}$ solution with mixtures of 4'-p-bromomethylphenyl-2,2':6',2"'-terpyridine and benzyl bromide. An almost quantitative conversion of the cellulose hydroxyl groups was reached when less than one terpyridine substituent was attached to the cellulose repeating units on average. At higher degrees of terpyridine substitution, some of the cellulose hydroxyl groups seem to remain unsubstituted. This conclusion has been drawn on the basis of NMR, IR and solubility measurements. We assume that steric hindrance of the bulky side groups is responsible for incomplete conversion. In a final step, the terpyridine substituents of the cellulose derivatives could be converted quantitatively into ruthenium(II) complexes via treatment with activated $\left[\mathrm{Ru}\left(\right.\right.$ tpy) $\left.\mathrm{Cl}_{3}\right]$ in $\mathrm{N}, \mathrm{N}$-dimethylacetamide/1-butanol (tpy: 2,2':6',2'-terpyridine).
\end{abstract}

\section{Introduction}

An important goal in polymer science is creating new pathways that allow a more extensive use of biopolymers in technical applications [1-13]. The formation of new functional polymers bearing ionic, electro- or photochromic, redox- or catalytically active side groups based on, for example, cellulose might open new perspectives in fields like optics, electronics and surface technology [1]. Therefore, we started a research program directed towards new synthetic procedures that open up access to well-defined cellulose derivatives bearing transition-metal complexes as lateral substituents. Attention should be paid in particular to procedures which allow both, the introduction of any amount of complexes - statistically distributed along and among the cellulose chains - and, simultaneously, substitution of all remaining cellulose hydroxyl groups by a second type of substituent R ('auxiliary substituent'). The latter groups $\mathrm{R}$ should avoid difficulties in subsequent characterization and processing steps.

In a first paper dealing with this topic, we reported on some ferrocene-containing cellulose derivatives $\mathbf{A}$ [14]. They were prepared from cellulose triacetate 1, a starting material which readily dissolves in dimethyl sulfoxide (DMSO) / $\mathrm{NaOH}$ solution. In this 
medium, its acetyl groups can be replaced easily and completely by other functional groups when treated with organic halides.
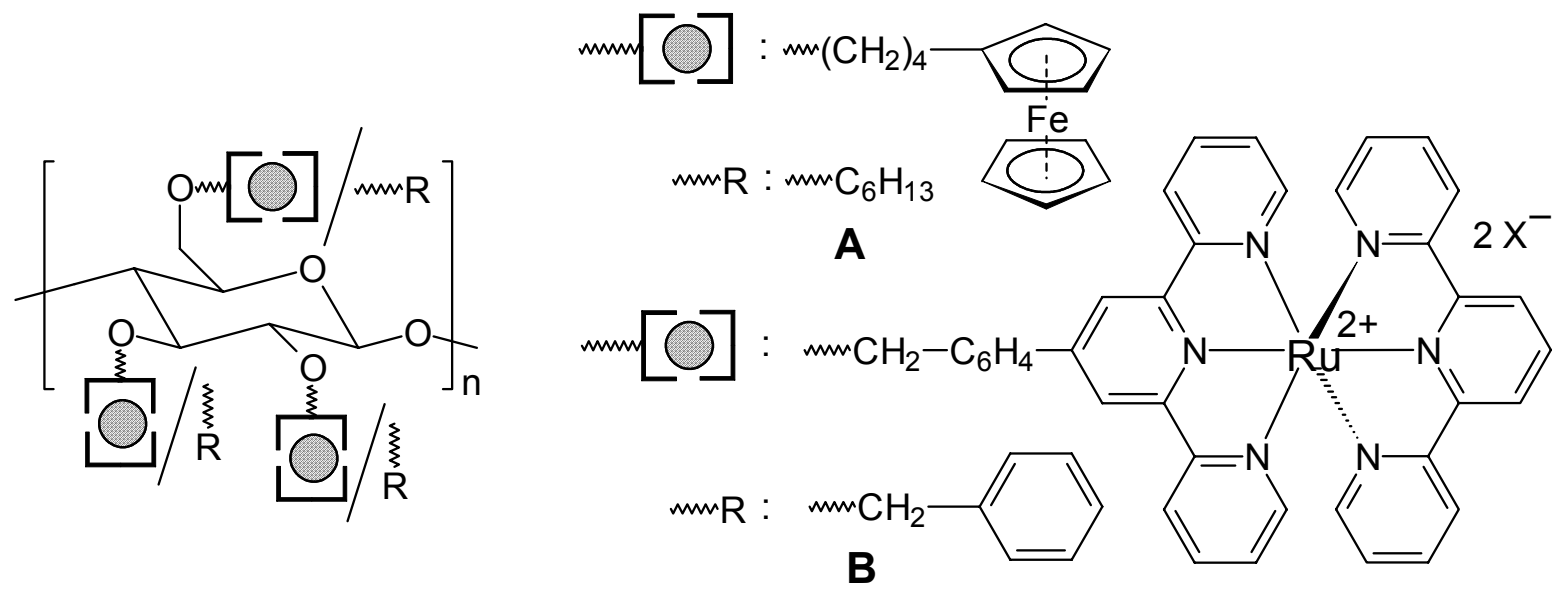

Fig. 1. Target polymers in our research program on metallo-celluloses
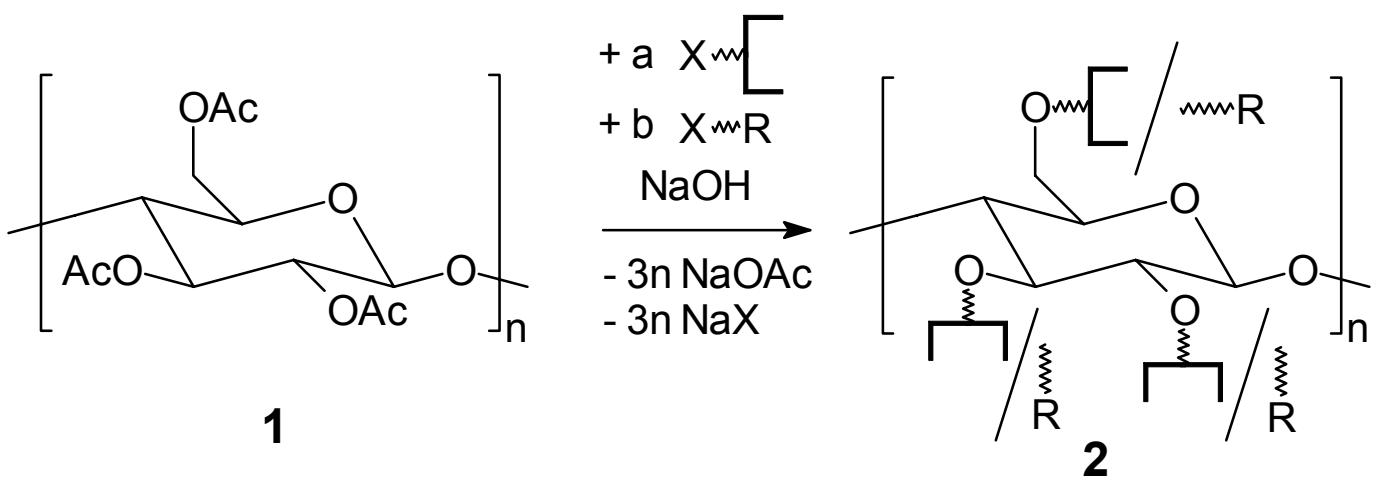

Ac: $\mathrm{CH}_{3}-\mathrm{CO}-$

$X$ : reactive functionality

$\mathrm{R}$ : alkyl or aryl moiety

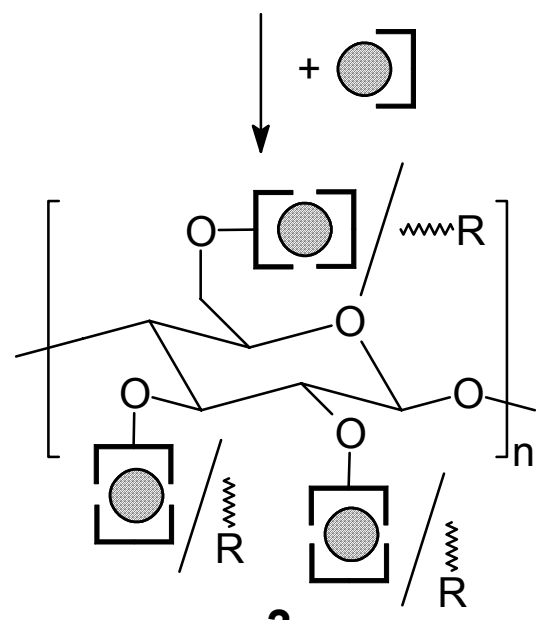

$\leftarrow$ : chelating ligand

○: transition-metal complex

3

Scheme 1. Schematic representation of the strategy to be used for the preparation of transition-metal-complex substituted cellulose derivatives 3

In the present contribution, we broaden the scope of that procedure towards cellulose derivatives B bearing benzyl auxiliary substituents and bis-terpyridine ruthenium(II) complexes. These latter pseudo-octahedrally coordinated species were judged to be 
the transition-metal substituents of choice for the present work because they can be formed under mild conditions in nearly quantitative yields [15]. This is of importance because complex formation is one of the planned macromolecular substitution reactions leading to the desired target polymers. Also, once formed, these complexes are thermodynamically very stable and kinetically inert. Thus, they allow a profound analysis of the constitution of the received materials. Last but not least, macromolecules containing ruthenium complexes are in general of considerable interest because of their electro-chemical, optical and catalytical properties [15].

In order to introduce ionic ruthenium(II) complexes into cellulose, a two-step procedure was selected (Scheme 1). In the first macromolecular substitution step, appropriately functionalized ligand moieties have to be attached to the cellulose backbone together with the inert auxiliary substituents $\mathrm{R}$. In the following step, the ligand moieties of $\mathbf{2}$ have to be converted into metal complexes via the treatment with a reactive transition-metal reagent.

\section{Results and discussion}

\section{Synthesis of starting materials}

4'- $p$-Benzyl-2,2':6',2"'-terpyridine moieties were selected as the ligands to be attached to the cellulose backbone. Benzyl bromide was the auxiliary substituent of choice to cap remaining cellulose hydroxyl groups. Hence, 4'- $p$-bromomethylphenyl-2,2':6',2"'terpyridine 7 was the reagent required for the introduction of the ligand moieties into precursor 1. At first, 7 was prepared according to the procedure shown in Scheme 2 $[16,17]$ : condensation of 2-acetylpyridine $\mathbf{4}, p$-tolylaldehyde $\mathbf{5}$, acetamide and ammonium acetate gave terpyridine derivative 6 in approx. 30\% yield. The methyl group of 9 was subsequently brominated using $N$-bromosuccinimide (NBS). A colourless solid material was obtained after recrystallization in $55 \%$ yield.<smiles>CC(=[OH+])c1ccc(C=O)cc1</smiles>

Scheme 2. One-pot synthesis of 4'-p-bromomethylphenyl-2,2':6',2"'-terpyridine 6 and its conversion into reagent 7 . The numbering of carbon atoms given for compound 7 is used for NMR signal assignment

NMR spectroscopy and mass spectrometry were applied to determine the constitution and the purity of the formed materials. As an example, Fig. 2 shows the aromatic region of the ${ }^{1} \mathrm{H}$ NMR spectra of compounds 6 and 7 together with the signal assignment. 
These spectra show that the desired products $\mathbf{6}$ and $\mathbf{7}$ are indeed formed as the main products. However, there are some further absorptions of minor intensity in these spectra - assigned by asterisks in Fig. 2 - which point towards side products formed during the synthesis of 6 . Mass spectrometry and elemental analysis showed the side products to have the same molar masses, and identical elemental compositions, as the main products. Profound NMR investigations, synthesis of reference compounds, and careful consideration of the literature [18] allowed the conclusion that these side products are constitutional isomers of terpyridine derivatives 6 and 7 , respectively: 6'-p-tolyl-2,2':4',2'-terpyridine 6 a (5 - 10\%; $\left.{ }^{1} \mathrm{H} \mathrm{NMR}\right)$ is formed in the first step of the synthetic sequence shown in Scheme 2, in addition to the desired product $\mathbf{6}$. Its formation can be rationalized by closer inspection of the mechanism according to which compound $\mathbf{6}$ is formed (Scheme 3 ).

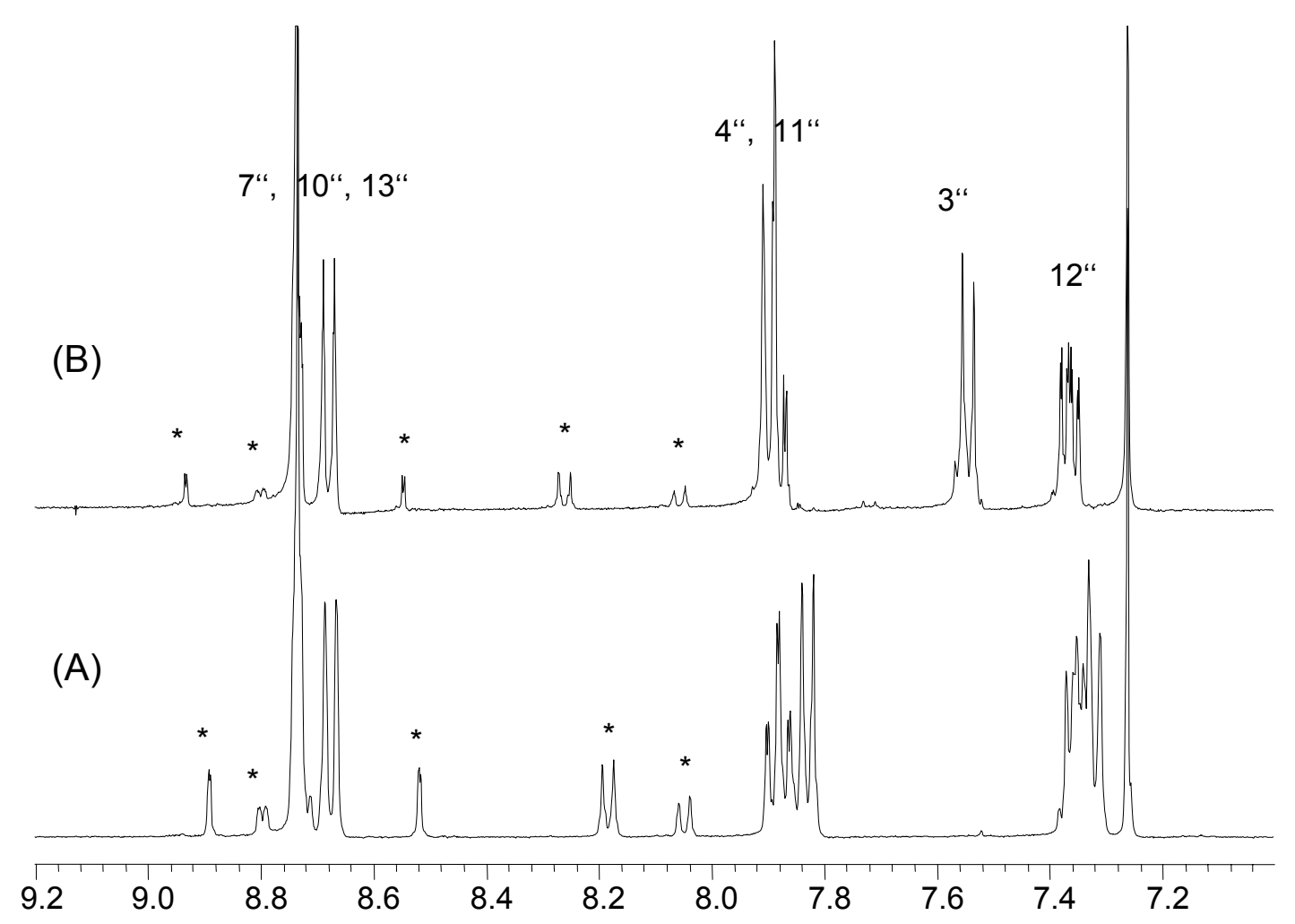

Fig. 2. ${ }^{1} \mathrm{H}$ NMR spectra of 4'-p-tolyl-2,2':6',2'terpyridine 6 (A), and of 4'-p-bromomethylphenyl-2,2':6',2'terpyridine 7 (B), obtained via the synthesis shown in Scheme 2; $\mathrm{CDCl}_{3}$, room temperature (r.t.)

At first, an aldol condensation of acetylpyridine $\mathbf{4}$ and tolylaldehyde 5 leads to intermediate 8. The chalcone derivative 8, however, can react with another acetylpyridine 4 in two different ways. According to pathway A, a Michael-analogous addition occurs, while in pathway B the acetylpyridine reacts with the carbonyl group of $\mathbf{8}$. Both processes result - via reaction with ammonia followed by dehydrogenation - in a central pyridine ring, but the position of the nitrogen atoms is different in the two products.

Despite much effort we were unable so far to lower the amount of this side product when 6 was prepared according to the process shown in Scheme 2. Therefore, we tested an alternative synthetic procedure for the preparation of 6 (Scheme 4) [19]: here, the chalcone derivative $\mathbf{8}$ is generated in advance under much milder 
conditions and thus can be isolated as a pure compound. Then, it is treated with 1-(2-pyridacyl)pyridinium iodide $\mathbf{1 0}$ which is easily accessible via the conversion of 2-acetylpyridine 4, pyridine and iodine. Here, the pyridinium moiety acts as an excellent leaving group and allows formation of $\mathbf{6}$ under very mild conditions, too. As is shown in Fig. 3, pure compounds $\mathbf{6}$ and $\mathbf{7}$ were obtained from this latter process.

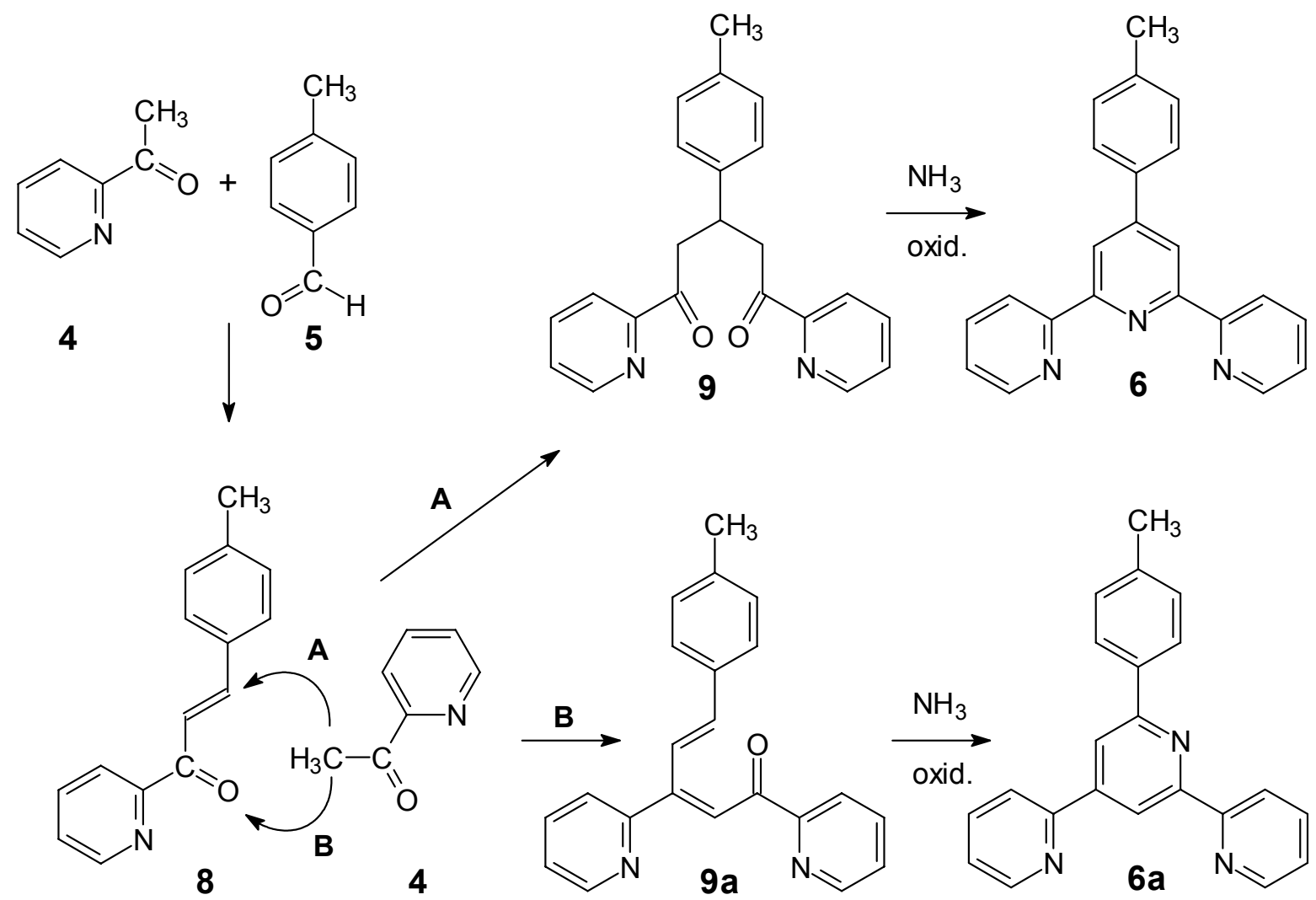

Scheme 3. Mechanistic details of the terpyridine synthesis according to Scheme 2<smiles>Cc1ccc(/C=C/C(=O)c2ccccn2)cc1</smiles>

8<smiles>O=C(C[n+]1ccccc1)c1ccccn1</smiles>

10<smiles>Cc1ccc(-c2cc(-c3ccccn3)nc(-c3ccccn3)c2)cc1</smiles>

6

Scheme 4. Improved synthesis of terpyridine derivative 6

\section{Model conversions}

The treatment of cellulose triacetate 1 with mixtures of 4'-p-bromomethylphenyl$2,2^{\prime}: 6^{\prime}, 2$ '-terpyridine 7 and benzyl bromide 11 in $\mathrm{DMSO} / \mathrm{NaOH}$ was believed to be the way of choice for the introduction of ligand moieties into cellulose (Scheme 5). 


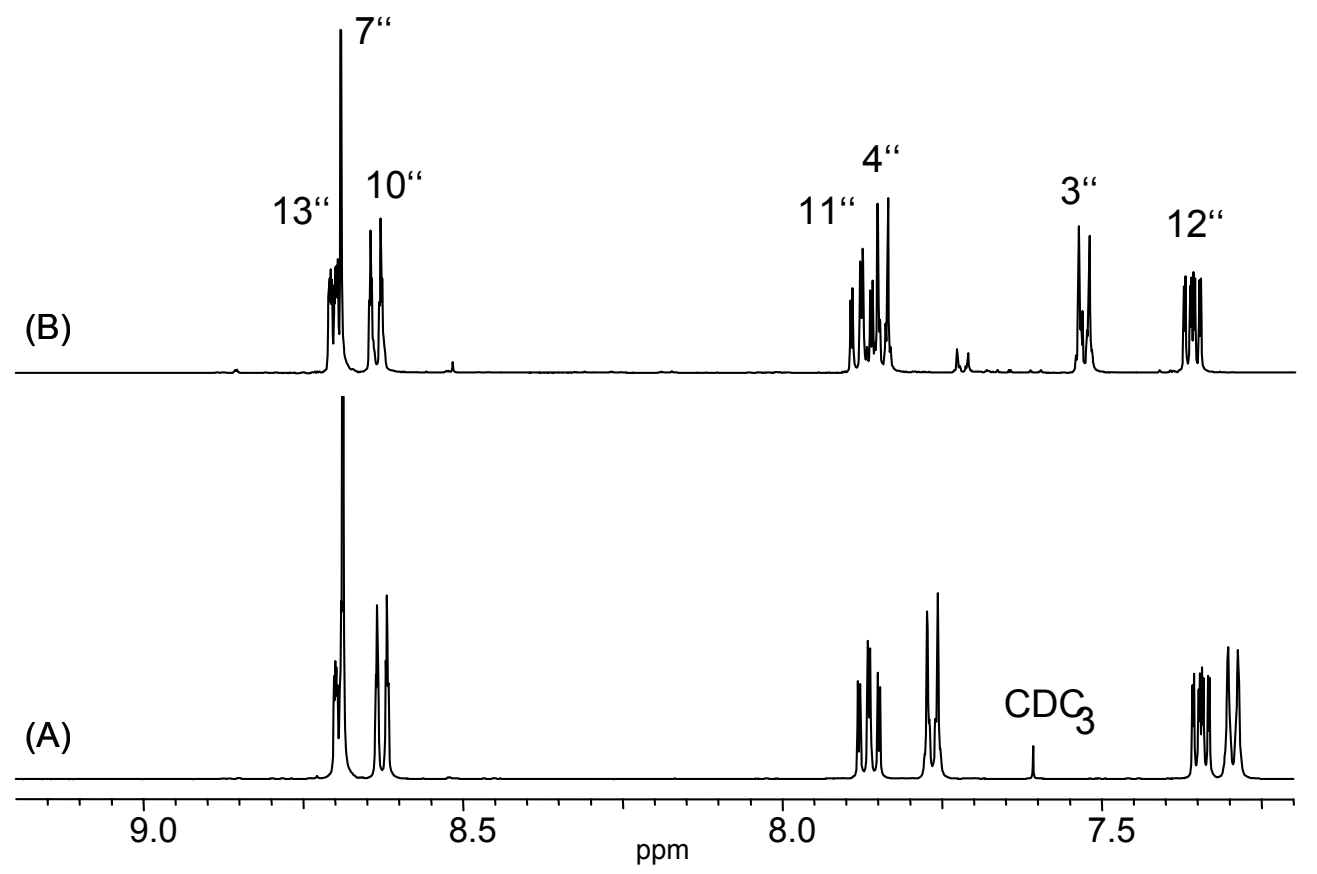

Fig. 3. ${ }^{1} \mathrm{H}$ NMR spectra of 4'-p-tolyl-2,2':6', 2"'-terpyridine 6 , and of 4'-p-bromomethylphenyl-2,2':6',2"-terpyridine 7, respectively, obtained according to Scheme $4\left(\mathrm{CDCl}_{3}\right.$ : DMSO- $d_{6} \approx 6: 1$ )

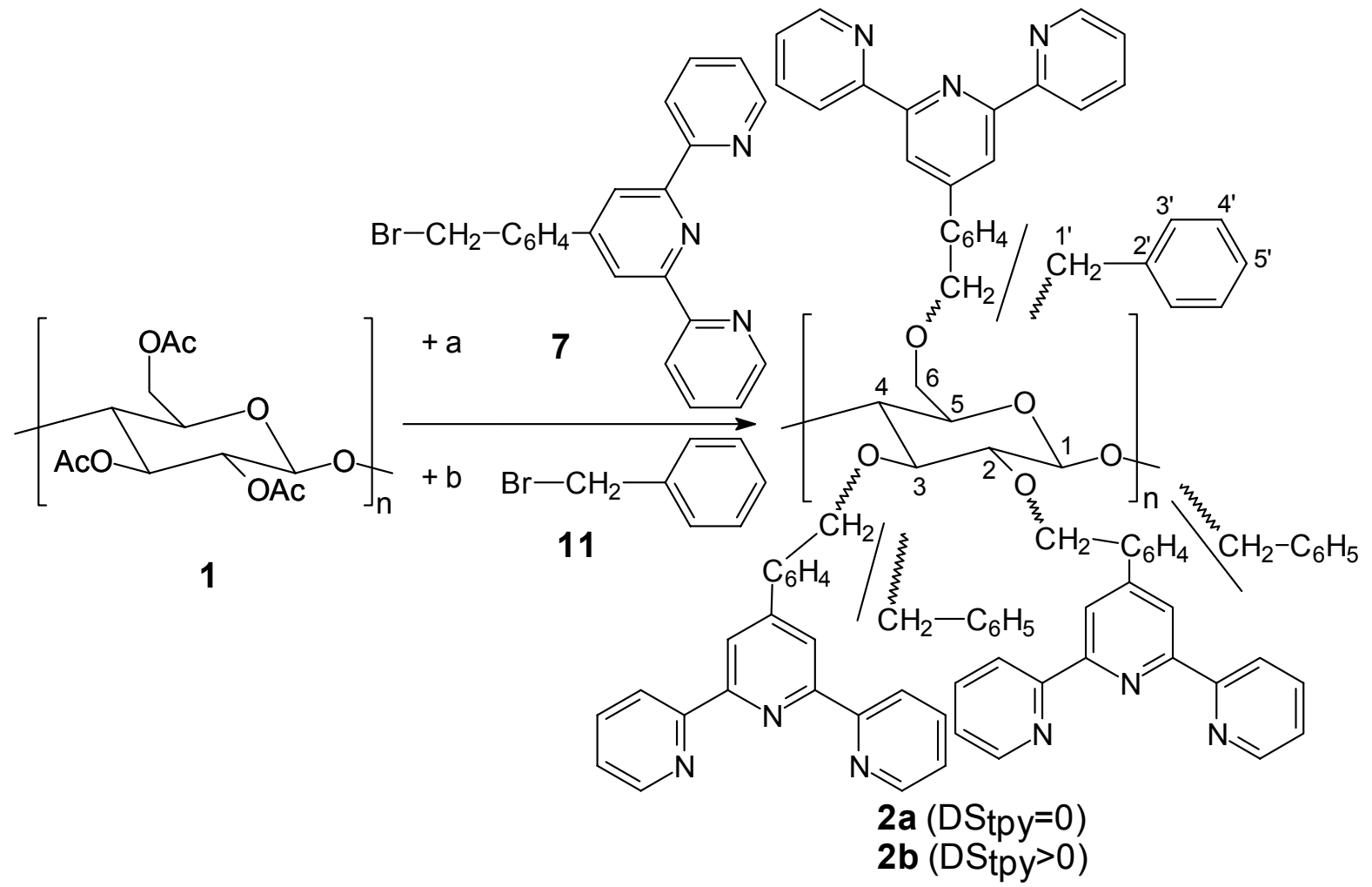

Scheme 5. Conversion of cellulose triacetate 1 into terpyridine-substituted cellulose derivatives 2. $\mathrm{DS}_{\mathrm{tpy}}$ is the degree of ligand substitution $\left(0 \leq \mathrm{DS}_{\mathrm{tpy}} \leq 3\right)$. The overall degree of substitution should be $\mathrm{DS}_{0}=3$

Two procedures are described in the literature for the efficient etherification of cellulose triacetate with benzylic bromides. In both cases, cellulose triacetate 1 is 
dissolved in dry DMSO, a twelve-fold excess of powdered $\mathrm{NaOH}$ is added, and the solution is stirred for one further hour. Finally, according to Kondo's procedure (method A) [20], 12 equiv. of benzylic bromide are added in small portions over a period of $5 \mathrm{~h}$. Subsequently, the reaction mixture is stirred at $70^{\circ} \mathrm{C}$ for 1 day. According to Wenz et al. (method B) [21], on the other hand, 12 equiv. of benzylic bromide are added at once, and the reaction mixture is stirred for 8 days at room temperature.

The aim of the following model experiments was to find out optimum reaction conditions for the synthesis of $\mathbf{2 b}$. Therefore, pure benzyl bromide $\mathbf{1 1}$ - which was selected as auxiliary reagent and should have a quite similar reactivity as compared to terpyridine reagent $\mathbf{7}$ - was applied as model reagent as well. It could be shown that both procedures give white powders of readily soluble cellulose derivatives $\mathbf{2 a}$ in $>80 \%$ after work-up - provided carefully powdered and dry $\mathrm{NaOH}$ is used. If, on the other hand, the conditions were not properly chosen, insoluble products were obtained. This insolubility was due to incomplete substitution of the cellulose hydroxyl groups, leading to intermolecular hydrogen bonds and thus physical crosslinking. Hence, solubility is a valuable first test of whether or not an overall degree of substitution of almost three is reached.

The products $2 a$ obtained under best conditions were characterized using NMR and IR spectroscopy. IR spectroscopy shows all absorptions expected for benzyl cellulose (Fig. 4): the signals corresponding to $\mathrm{CH}$ and $\mathrm{CH}_{2}$ valence vibrations appear at approx. $2900-3100 \mathrm{~cm}^{-1}$, and the broad absorption at $1100 \mathrm{~cm}^{-1}$ is due to $\mathrm{C}-\mathrm{O}-\mathrm{C}$ stretching vibrations. Characteristic for mono-substituted benzene derivatives are the signals at $730 \mathrm{~cm}^{-1}$ (C-H deformation) and $695 \mathrm{~cm}^{-1}$ (ring deformation). Moreover, after careful drying, the materials did not show any absorption around $3400 \mathrm{~cm}^{-1}$ which would be characteristic for remaining cellulose hydroxyl groups. This is a good evidence for a very high degree of substitution reached under the applied conditions.

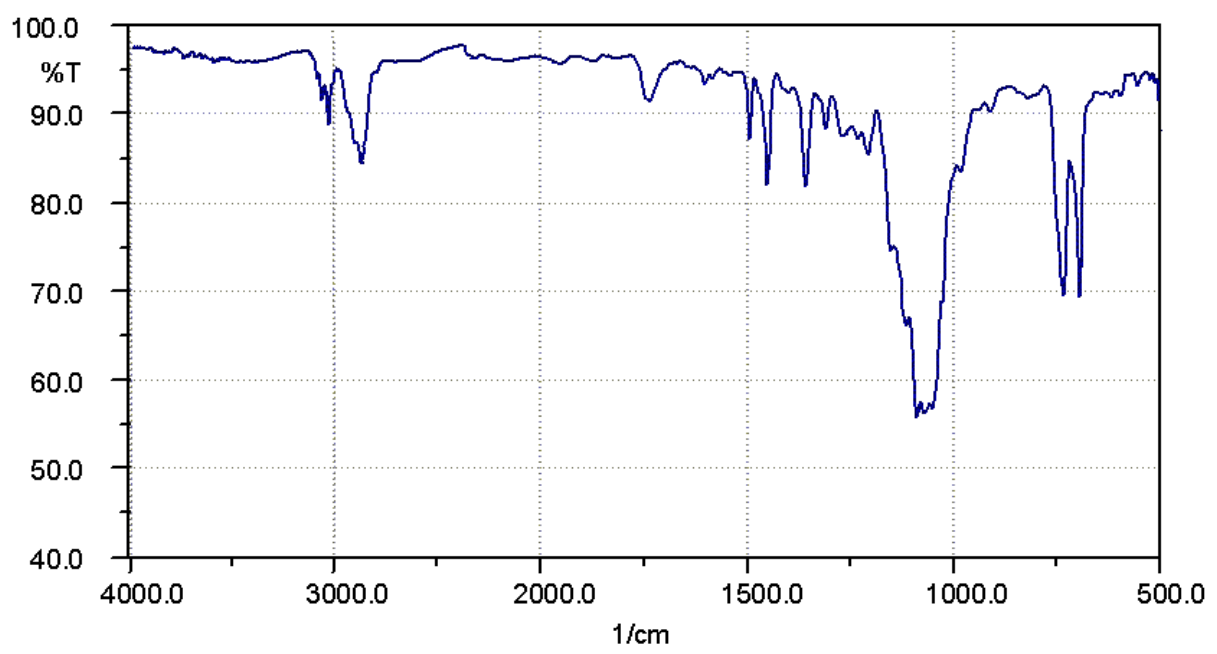

Fig. 4. IR spectrum of a benzyl cellulose $2 \mathbf{a}$ having a $\mathrm{DS}_{0}$ of approx. 3

${ }^{1} \mathrm{H}$ and ${ }^{13} \mathrm{C}$ NMR spectra as well proved the homogeneous constitution and the high degrees of substitution of the obtained benzyl celluloses $2 \mathrm{a}$. Using DEPT, ${ }^{1} \mathrm{H}-{ }^{13} \mathrm{C}$ hetero-COSY and ${ }^{1} \mathrm{H},{ }^{13} \mathrm{C}$ shift correlation spectra, a full signal assignment could be done for both, proton and carbon spectra. No hints could be found for remaining 
hydroxyl groups or side reactions. In order to compare chain degradation under the respective conditions, however, neither IR nor NMR spectroscopy are appropriate methods. Hence, size exclusion chromatography (SEC) and viscometry were additionally applied. Two representative SEC traces of benzyl celluloses $\mathbf{2 a}$ are shown in Fig. 5.

One sample was prepared according to method A, the second one by method B. Clear differences in the molar masses are evident, and it was a reproducible result that the materials obtained after 1 day reaction time at $70^{\circ} \mathrm{C}$ had clearly higher molar masses as compared to those prepared at room temperature within 7 days.

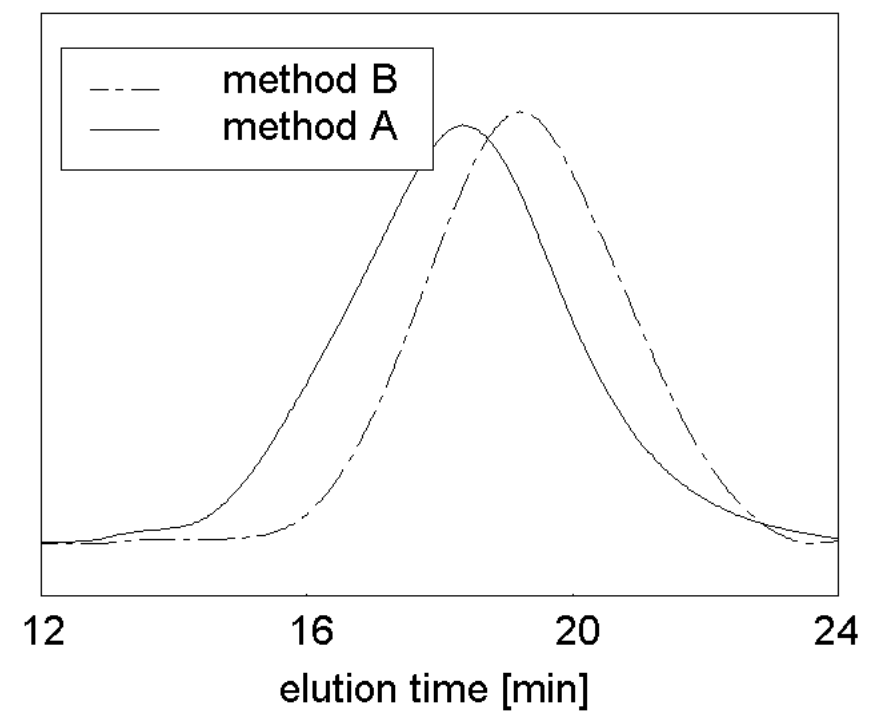

Fig. 5. SEC traces of benzyl celluloses $2 a$, prepared according to methods $A$ and $B$, respectively. SEC traces were recorded at $30^{\circ} \mathrm{C}$ in tetrahydrofuran (THF)

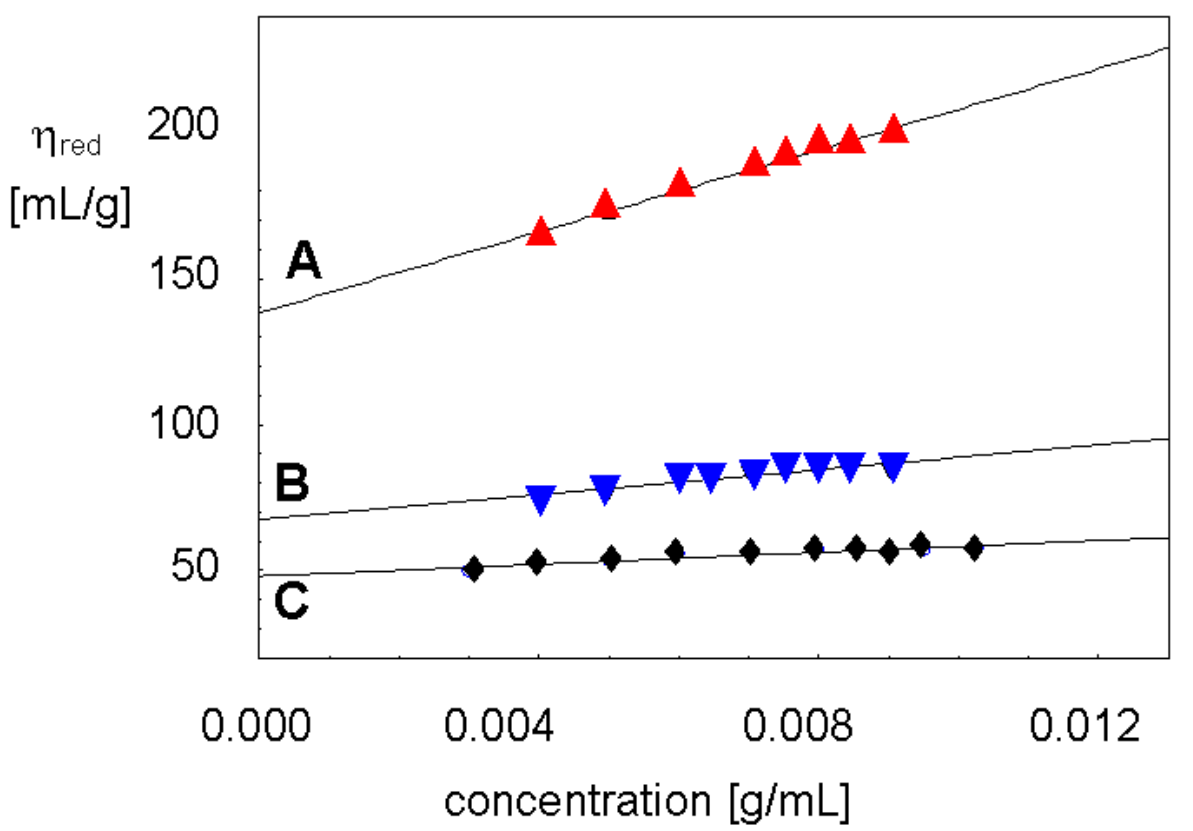

Fig. 6. Huggins plots of benzyl celluloses $2 \mathbf{a}$, prepared according to methods A (A: 1 day at $\left.70^{\circ} \mathrm{C}\right)$ and $B(B: 8$ days; $C: 14$ days at r.t.), respectively. Measurements were performed in $\mathrm{CHCl}_{3}$ at $30^{\circ} \mathrm{C}$ 
Viscometry reconfirmed the results of SEC measurements: benzyl celluloses $\mathbf{2 a}$ prepared at $70^{\circ} \mathrm{C}$ had much higher intrinsic viscosities than those obtained at room temperature (Fig. 6). As expected, moreover, chain degradation was shown to be even stronger when stirring at room temperature was continued for 14 days. The observation that conversion at elevated temperatures gives lower chain degradation than reactions at room temperature is in clear contrast to the results found for n-hexyl celluloses [15]. There, the samples obtained via method B had the clearly higher molar masses. This difference might be the result of a faster hydrolysis of benzyl bromides as compared to aliphatic bromides, but there is no final proof of this explanation available so far. To summarize the model studies, Tab. 1 collects the relevant analytical data obtained for benzyl celluloses $\mathbf{2} \mathbf{a}$.

Tab. 1. Selected analytical data obtained for benzyl celluloses $2 a$

\begin{tabular}{|c|c|c|c|c|}
\hline Sample & Method & Yield in \% & $M_{\mathrm{w}}$ in $\mathrm{g} / \mathrm{mol}^{\mathrm{a})}$ & {$[\eta]$ in $\mathrm{mL} / \mathrm{g}$} \\
\hline $2 a(1)$ & $70^{\circ} \mathrm{C}, 1$ day & 69 & 154000 & 138 \\
\hline $2 a(2)$ & $25^{\circ} \mathrm{C}, 8$ days & 86 & 97000 & 68 \\
\hline $2 a(3)$ & $25^{\circ} \mathrm{C}, 14$ days & 76 & 68000 & 48 \\
\hline
\end{tabular}

a) Molar masses were determined using SEC in THF, calibrated vs. polystyrene.

As we expected a reactivity of 4'-p-bromomethylphenyl-2,2':6',2'-terpyridine 7 quite similar to that of benzyl bromide 11, we decided to test method $A$ for the preparation of terpyridine-containing cellulose derivatives $\mathbf{2} \mathbf{b}$ at first.

\section{Synthesis of terpyridine- and benzyl-substituted cellulose ethers}

For the simultaneous introduction of 4'-p-benzyl-2,2':6',2"'-terpyridine and benzyl side groups, cellulose triacetate 1 was treated with mixtures of 4'-p-bromomethylphenyl$2,2^{\prime}: 6^{\prime}, 2^{\prime \prime}$-terpyridine 7 and benzyl bromide 11 in $\mathrm{DMSO} / \mathrm{NaOH}$ solution at $70^{\circ} \mathrm{C}$ (see Scheme 5). The ratio of the reagents was varied over a wide range. During all these conversions, the originally colourless mixtures turned quickly into dark violet but remained homogeneous over the whole reaction time. After 1 day at $70^{\circ} \mathrm{C}$, however, it was impossible to isolate polymeric material by pouring the whole reaction mixture into methanol or water - the first step in the standard work-up procedure. Obviously, the formed polymers were either readily soluble in water or the cellulose backbones were degraded during the conversions. In n-hexane, on the other hand, some dark violet solid material could be isolated. NMR spectroscopy of those solids led to the conclusion that a considerable amount of the terpyridine groups had undergone the Menschutkin side reaction [22]: some of the pyridine nitrogen atoms were quaternized by bromomethylene functionalities of 7 or 11 (Scheme 6), leading to cellulose polyelectrolytes which readily dissolve in water.

Hence, we had to apply milder reaction conditions for the macromolecular substitution reaction in order to prevent quaternization simultaneously with the ether formation. Lowering the reaction temperature and increasing the reaction time was found to be the measure of choice: finally, the original method B, i.e., stirring the reaction mixture for 8 days at room temperature, proved to be the best procedure. Under these conditions, only slightly violet powders were obtained by precipitation in 
methanol/water. After work-up and drying, parts of the polymers were found to be insoluble. The respective amount increased with increasing $D_{\text {tpy: while there was }}$ almost no insoluble part when $\mathrm{DS}_{\text {tpy }} \leq 1$, the material was almost insoluble when values of $D_{\text {tpy }}$ greater than approx. 2.5 were aimed at. We interpret this result as a consequence of incomplete substitution of the cellulose hydroxyl groups when larger amounts of terpyridine groups are attached to the cellulose chains: due to their bulkiness, they seem to affect the substitution of neighbouring hydroxyl functions and thus cause physical crosslinking via intermolecular hydrogen bonds. This explanation was further supported by IR spectroscopy where absorptions could be observed in the $3400 \mathrm{~cm}^{-1}$ region for the insoluble product fractions. All subsequent investigations were carried out using the soluble part of the products.

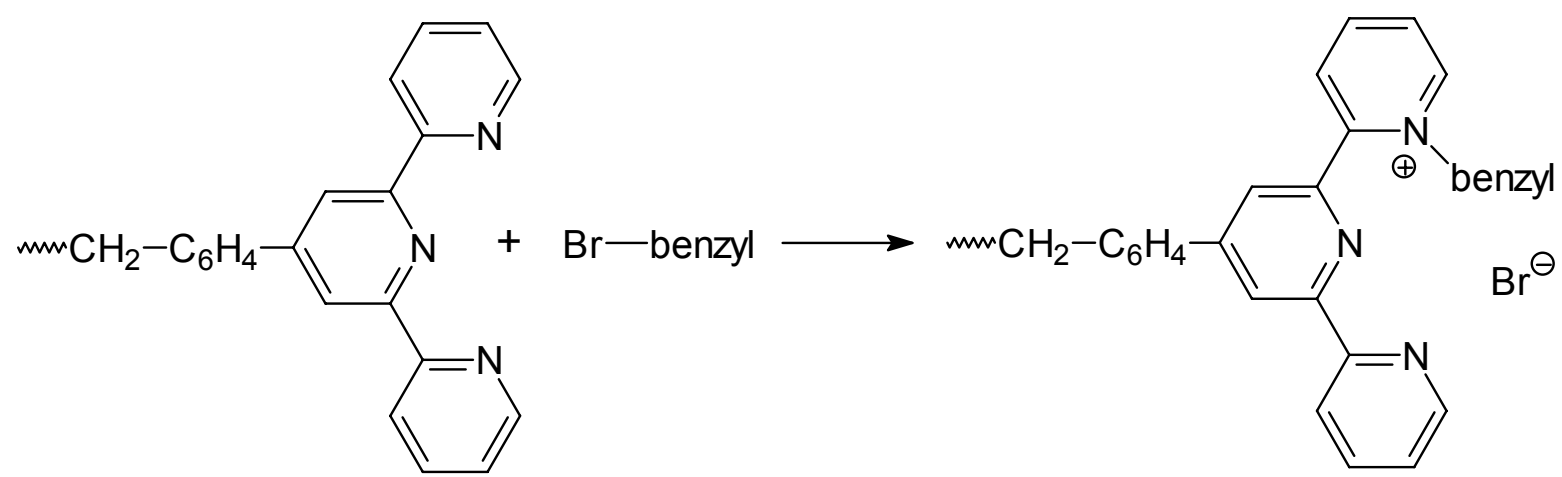

Scheme 6. Menschutkin side reaction observed during the conversion of cellulose triacetate 1 with mixtures of 7 and 11 in $\mathrm{NaOH} / \mathrm{DMSO}$ at $70^{\circ} \mathrm{C}$

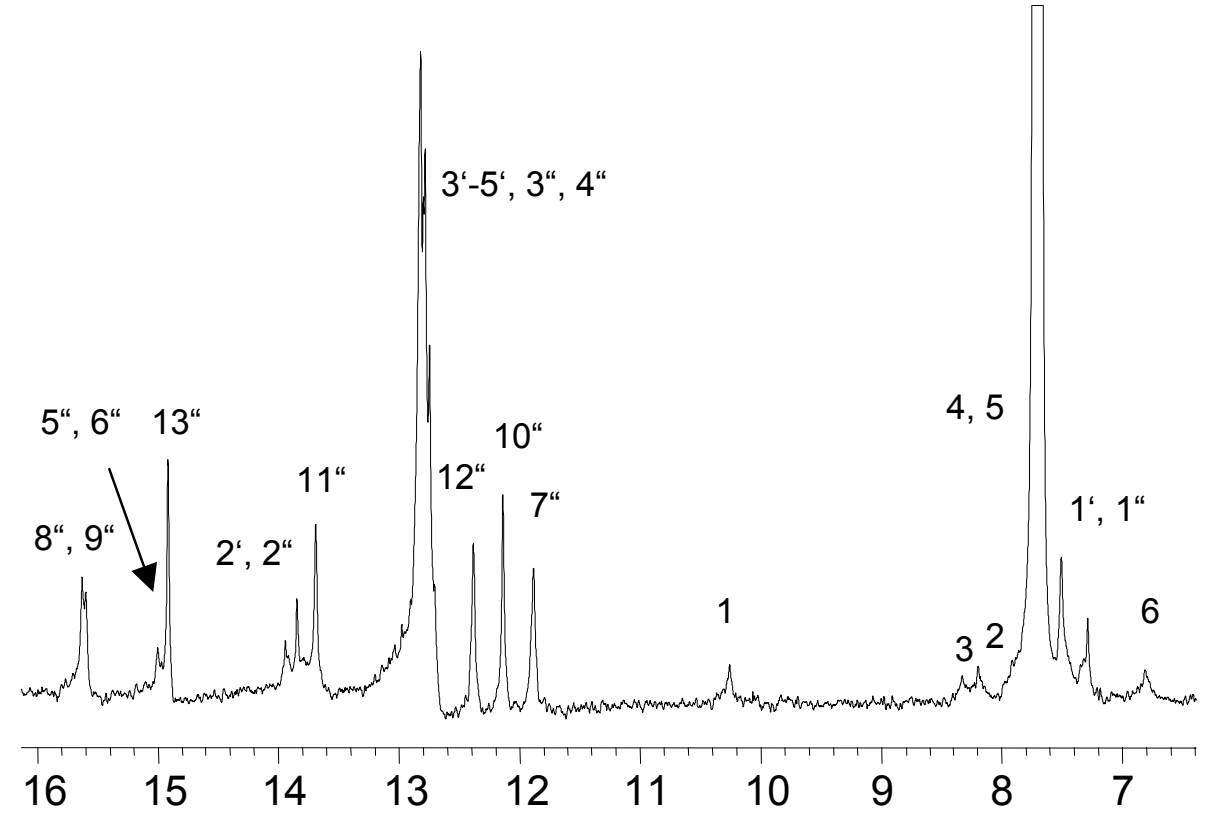

Fig. $7 .{ }^{13} \mathrm{C}$ NMR spectrum of a cellulose derivative $2 \mathbf{b}$ having a $\mathrm{DS}_{\text {tpy }} \approx 0.7 ; \mathrm{CDCl}_{3}$, room temperature

The proton NMR spectra (Fig. 8A) as well as the carbon spectra (Fig. 7) proved the formation of the desired terpyridine-substituted cellulose derivatives $\mathbf{2} \mathbf{b}$. No evidence was found in these spectra of side reactions such as quaternization processes. 
Moreover, comparison of the ${ }^{1} \mathrm{H}$ NMR signal intensities allowed a rough estimate of the ratio of the two different substituents attached to the chains.

\section{Introduction of ruthenium(II) complexes into precursor celluloses $\mathbf{2} \mathbf{b}$}

The introduction of ruthenium(II) complexes into the terpyridine-substituted cellulose precursors $\mathbf{2} \mathbf{b}$ should be achieved by the process shown in Scheme 6 . Here, an activated ruthenium complex $\left[\mathrm{Ru}(\text { tpy)(acetone) })_{3}\right]^{3+} 15$, which already bears one $2,2^{\prime}: 6^{\prime}, 2$ ''-terpyridine ligand (tpy) was the metal reagent of choice. 15 is available via conversion of $\left[\mathrm{Ru}(\mathrm{tpy}) \mathrm{Cl}_{3}\right] 14$ with $\mathrm{AgBF}_{4}$ in acetone solution and is known to react efficiently and highly selectively with a further free terpyridine ligand. In some trial experiments, first, we selected the best reaction conditions for this conversion.

In particular a reaction medium must be found which ensures homogeneous dissolution of the precursor celluloses $2 b$, of the metal-complex reagent 15 , and of the resulting metal-complex celluloses 3 . Moreover, the complexation should occur under the mildest possible conditions to give well-defined products. Finally, mixtures of $N, N$ dimethylacetamide (DMAc) and 1-butanol were found to be the optimum reaction medium: the terpyridine-substituted cellulose derivatives $\mathbf{2} \mathbf{b}$ were dissolved in this mixture, and the reddish-violet $\left[\mathrm{Ru}(\text { tpy)(acetone) })_{3}\right]^{3+} 15$ was added dropwise in 1-butanol solution (Scheme 7). After $24 \mathrm{~h}$ stirring at $70^{\circ} \mathrm{C}$, the formed product was precipitated by adding aqueous $\mathrm{NaCl}$ to the homogeneous reaction mixture. The obtained dark red powders redissolved easily and completely in, for example, DMSO. The ${ }^{1} \mathrm{H}$ NMR spectra proved the successful conversions according to Scheme 6 (see Fig. 8B): the observed changes of the ${ }^{1} \mathrm{H}$ NMR chemical shifts upon conversion $\mathbf{2} \mathbf{b}+$ $15 \rightarrow 3$ are characteristic for a successful complexation process, and the lack of absorptions corresponding to the free terpyridine ligands (see Fig. 8A) makes evident a nearly quantitative complex formation.

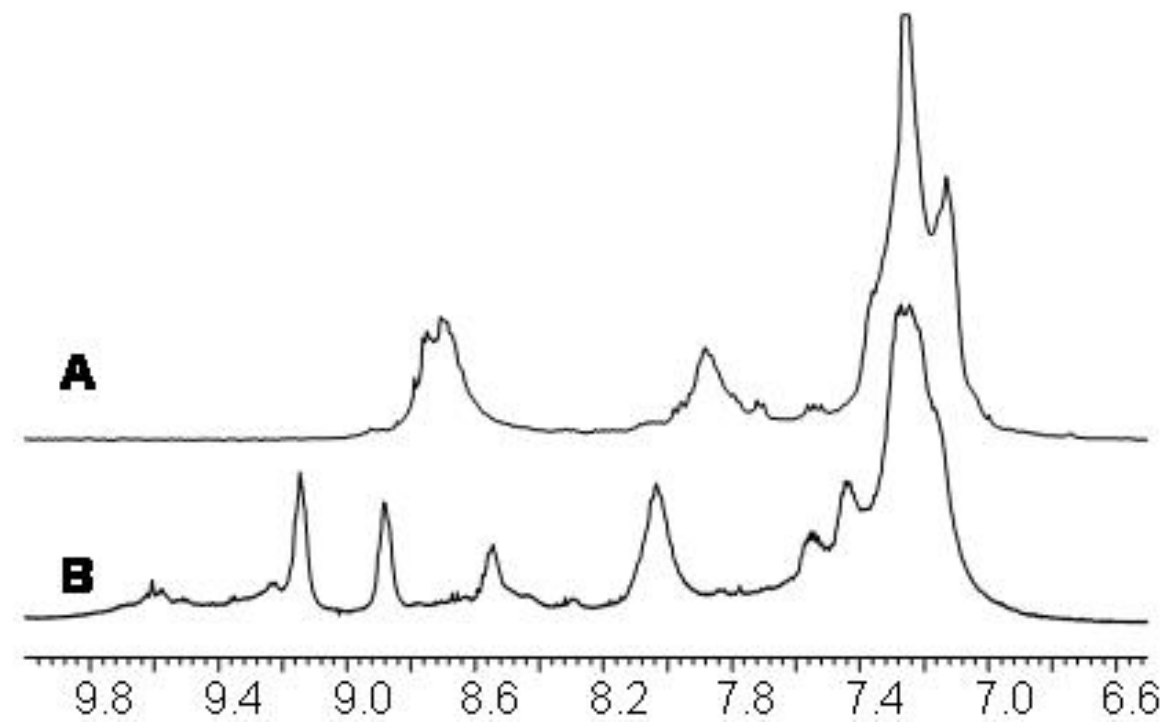

Fig. 8. ${ }^{1} \mathrm{H}$ NMR spectrum of precursor polymer $\mathbf{2 b}(\mathrm{A})$ and of metallo-cellulose derivative $3(\mathrm{~B})$, recorded in $\mathrm{CDCl}_{3}(\mathrm{~A})$ and DMSO-d $d_{6}(\mathrm{~B})$

In the proton NMR spectrum of precursor $\mathbf{2 b}$ (Fig. $8 \mathrm{~A}$ ) there are observable - at $\delta=$ 7.0 - $7.4 \mathrm{ppm}$ - the intensive absorptions of the aromatic protons of the auxiliary substituents as well as those of protons $\mathrm{H}^{3 "}$ and $\mathrm{H}^{12}$ of the terpyridine moiety. 


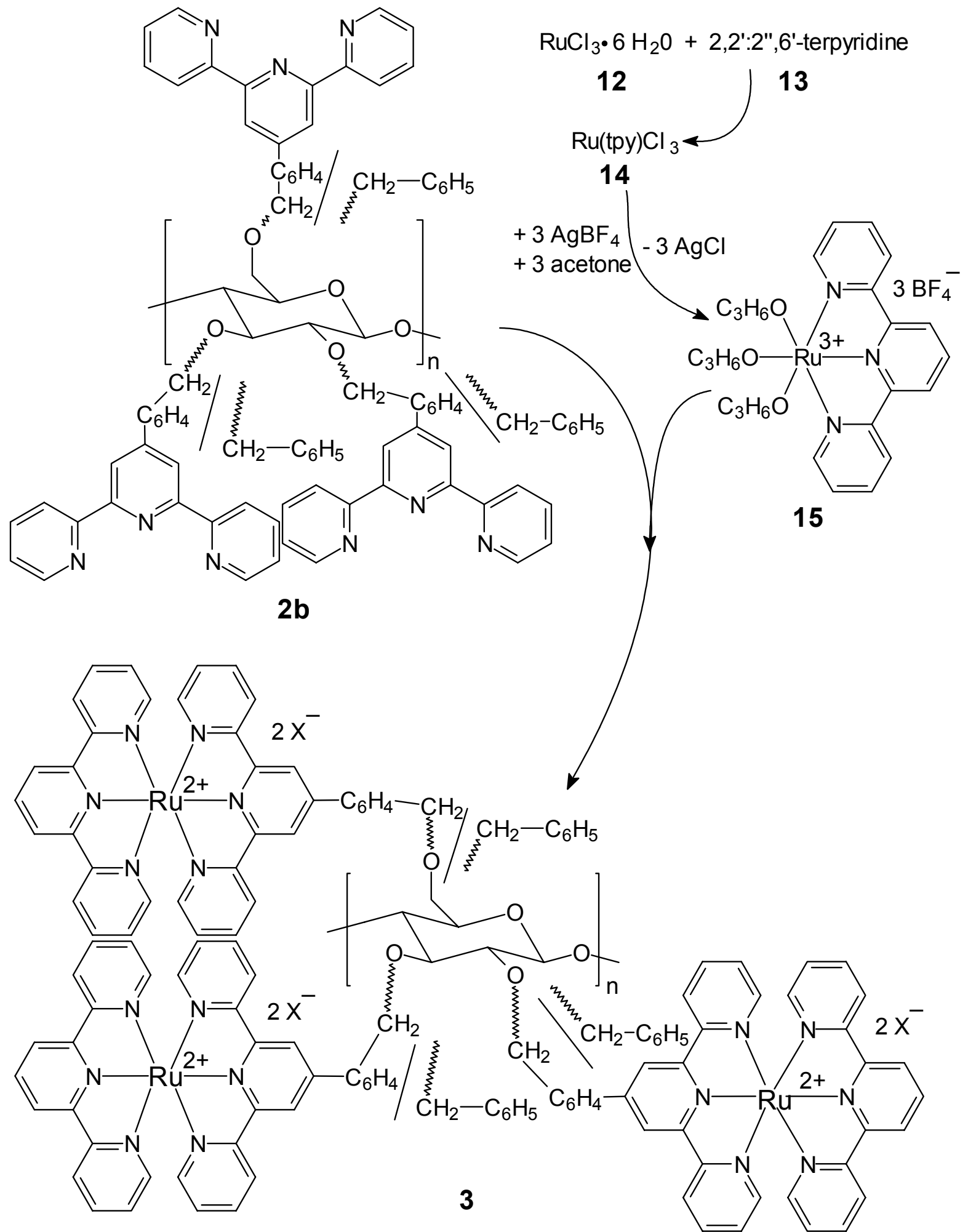

Scheme 6. Macromolecular substitution reaction used for the introduction of ruthenium(II) complexes into the terpyridine-substituted cellulose $\mathbf{2} \mathbf{b} ; \mathrm{X}^{-}=\mathrm{BF}_{4}{ }^{-}$after conversion and $\mathrm{Cl}^{-}$after precipitation

Moreover, broad signals are found at $\delta \approx 7.9 \mathrm{ppm}\left(\mathrm{H}^{4 ", 11 "}\right)$ and $8.7 \mathrm{ppm}\left(\mathrm{H}^{7 ", 10^{\prime \prime}, 13^{\prime \prime}}\right)$. When precursor $\mathbf{2 b}$ is successfully converted into the metal-complex polymer $\mathbf{3}$, only the aromatic absorptions assigned to the protons of the benzyl substituents maintain their chemical shifts. All other aromatic absorptions change in their chemical shifts, a 
characteristic feature of successful complex formation. At $\delta \approx 8.5,8.9$ and $9.1 \mathrm{ppm}$ now appear readily resolved absorptions that can be assigned to the protons $\mathrm{H}^{11}$, $\mathrm{H}^{13^{\prime \prime}}$ and $\mathrm{H}^{7 "}, 10$ ", respectively, as well as to the corresponding protons of the second terpyridine ligand which is introduced via the ruthenium species 15.

${ }^{13} \mathrm{C}$ NMR spectra were recorded as well for polymers $\mathbf{2 b}$ and $\mathbf{3}$. However, due to the low polymer concentration required to prevent gelation, the signal-to-noise ratios were not satisfying and inappropriate to any profound discussion even when FIDs were accumulated for hours. Moreover, the weak signals found in these spectra show - in full agreement with ref. [23] - that the ${ }^{13} \mathrm{C}$ chemical shifts do not change significantly upon complexation.

Finally, polymers $\mathbf{2 b}$ and $\mathbf{3}$ were characterized by SEC, using THF as the mobile phase. For precursor polymers $\mathbf{2 b}$ as well as for metal-complex polymers $\mathbf{3}$, monomodal but very broad elution curves were obtained. Moreover, the metal-containing cellulose derivates 3 gave slightly lower elution times as compared to the respective precursor polymers used for their preparation. This is most probably the result of slight chain degradation during complex-formation. On the other hand, it is also possible that ionic interactions lead to a coil contraction in polymers 3 . However, this latter explanation seems rather improbable because addition of $\mathrm{LiCl}$ to the mobile phase did not change the chromatograms significantly. A quantitative evaluation of the chromatograms was not carried out due to the lack of an appropriate standard for calibration.

\section{Conclusions and outlook}

Simultaneous conversion of cellulose triacetate with 4'-p-bromomethylphenyl$2,2 ': 6$ ',2"-terpyridine and benzyl bromide is shown to be an efficient method for the attachment of 4'-p-benzyl-2,2':6',2"'-terpyridine and benzyl side groups to a cellulose backbone. An almost quantitative conversion of the cellulose hydroxyl groups was reached when less than one terpyridine substituent was attached to the cellulose repeating units on average. At higher degrees of terpyridine substitution, some of the cellulose hydroxyl groups seem to remain unsubstituted. This conclusion has been drawn on the basis of NMR, IR and solubility measurements. We assume that steric hindrance of the bulky side groups is responsible for incomplete conversion. In a final step, the terpyridine substituents of the cellulose derivatives could be converted quantitatively into ruthenium(II) complexes via treatment with activated $\left[\mathrm{Ru}(\mathrm{tpy}) \mathrm{Cl}_{3}\right]$ in DMAc/1-butanol.

\section{Experimental part}

\section{Materials}

All chemicals and solvents were purchased from Acros, Aldrich, Fluka and Lancaster Chemical Co. and used without further purification unless otherwise stated. In order to remove peroxide impurities and oxygen, THF was refluxed with sodium or calcium hydride, and distilled under nitrogen.

\section{Methods}

NMR spectra were recorded at room temperature using a Bruker AM 400 NMR spectrometer working at $400 \mathrm{MHz}\left({ }^{1} \mathrm{H}\right)$ and $100 \mathrm{MHz}\left({ }^{13} \mathrm{C}\right)$, and a Bruker AM 500 
NMR spectrometer working at $500 \mathrm{MHz}\left({ }^{1} \mathrm{H}\right)$ and $125 \mathrm{MHz}\left({ }^{13} \mathrm{C}\right)$. Signal assignment was done according to the numbering given in Schemes 2 and 5. Multiplicities were given as ' $s$ ' for singlet, ' $d$ ' for doublet, ' $t$ ' for triplet, ' $q$ ' for quartet, and ' $m$ ' for multiplet. Tetramethylsilane was the internal standard. IR spectra were recorded on a Shimadzu FTIR-810M as films, prepared from chloroform solution on $\mathrm{KBr}$ plates under nitrogen. SEC chromatograms were recorded in THF (1\% toluene as internal standard) on a system consisting of a Waters 510 pump, a TSP AS 100 injector and PL Mixed Gels B, C and D columns (Polymer Laboratories). Detection was achieved using a Waters RI 410 differential refractometer and a Waters UV-vis 486 detector. The solutions were filtered through PTFE filters (Acrodish GF, $0.45 \AA$ ). SEC data were collected using the WINGPC V. 6.01 software. Polystyrene was used as the standard. Elemental analyses were carried out using a Perkin Elmer 240B instrument and a CHN-Rapid instrument of Elementar Analysensysteme. Viscosity investigations were carried out on a PVS 2.03 of the Lauda company, using an Ubbelohde capillary viscometer (type Oc). Chloroform was the solvent; the temperature was $30^{\circ} \mathrm{C}$.

\section{4'-p-Tolyl-2,2':6',2"'-terpyridine 6}

\section{Method $1[16,17]$}

In a $500 \mathrm{~mL}$ reaction vessel, acetamide $(71 \mathrm{~g}, 1.2 \mathrm{~mol})$ ammonium acetate $(46 \mathrm{~g}, 0.6$ mol), p-tolylaldehyde ( $5 \mathrm{~mL}, 0.042 \mathrm{~mol})$ and 2-acetylpyridine $(9 \mathrm{~mL}, 0.08 \mathrm{~mol})$ were stirred and refluxed for $2 \mathrm{~h}$ under an atmosphere of nitrogen. After cooling down to $120^{\circ} \mathrm{C}$, a solution of $\mathrm{NaOH}(35 \mathrm{~g})$ in water $(75 \mathrm{~mL})$ was added. Stirring and refluxing was continued for further $2 \mathrm{~h}$. The black, rubber-like raw-product was dissolved in a small quantity of acetic acid, and the same volume of concentrated hydrobromic acid ( $48 \%$ in water) was added. The formed hydrobromide salt was filtered off. Water was added to the solid, and the $\mathrm{pH}$ was adjusted to $7-8$ using $4 \mathrm{M} \mathrm{KOH}$. The aqueous layer was extracted using $\mathrm{CH}_{2} \mathrm{Cl}_{2}$ until the organic layer was colourless. The organic layer was concentrated down to dryness, and the dark violet residue was recrystallized from ethanol. The formed white crystal needles were dried in vacuum. The yield was $3.72 \mathrm{~g}(0.012 \mathrm{~mol}, 30 \%)$.

\section{Method 2 [19]}

1-Pyridin-2-yl-3-p-tolylpropenone and 1-(2-pyridacyl)pyridinium iodide were prepared according to the literature $[19,24]$. Ammonium acetate $(89.07 \mathrm{~g}, 1.975 \mathrm{~mol})$, 4-methyl2'-azachalcone $(10.00 \mathrm{~g}, 0.0448 \mathrm{~mol})$ and 1-(2-pyridacyl)pyridinium iodide (14.61 g, $0.0449 \mathrm{~mol}$ ) were mixed with vigorous stirring and refluxed for $10 \mathrm{~h}$ in conc. acetic acid $(89.5 \mathrm{~mL})$. After cooling down to room temperature, a solid precipitated from the dark green solution. It was filtered off and dried. After recrystallization from ethanol, bright needles were obtained, which were dried in vacuum $\left(\mathrm{P}_{4} \mathrm{O}_{10}\right)$. The yield was $7.61 \mathrm{~g}$ (m.p.: $158^{\circ} \mathrm{C}$ (lit.: $\left.158-159^{\circ} \mathrm{C}\right)$ ).

${ }^{1} \mathrm{H} \mathrm{NMR}\left(\mathrm{CDCl}_{3}\right): \delta=2.34(\mathrm{~s}, 3 \mathrm{H}, \mathrm{H} 13) ; 7.4$ - $7.3(\mathrm{~m}, 4 \mathrm{H}, \mathrm{H} 2, \mathrm{H} 11) ; 7.9-7.8(\mathrm{~m}, 4 \mathrm{H}$, $\mathrm{H} 3, \mathrm{H} 10) ; 8.67(\mathrm{~m}, 2 \mathrm{H}, \mathrm{H} 4) ; 8.73(\mathrm{~m}, 3 \mathrm{H}, \mathrm{H} 1, \mathrm{H} 7)$.

${ }^{1} \mathrm{H}$ NMR (DMSO- $\left.d_{6}: \mathrm{CDCl}_{3} \approx 1: 6\right): \delta=2.40$ (s, 2H, H13); 7.29 (d, 2H, H11); 7.35 (dt, $2 \mathrm{H}, \mathrm{H} 2) ; 7.77$ (d, 2H, H10); 7.87 (dt, 2H, H3); 8.62 (d, 2H, H4); 8.69 (s, 2H, H7); 8.70 (d, 2H, H1). 
${ }^{13} \mathrm{C} \mathrm{NMR}\left(\mathrm{CDCl}_{3}\right): \delta=32.952$ (C13); 118.91 (C7); 121.64 (C4); 124.06 (C2); 127.44 (C10); 129.93 (C11); 135.75 (C9); 137.14 (C3); 139.38 (C8); 149.40 (C1); 150.46 (C12); 156.15, 156.64 (C5, C6).

${ }^{13} \mathrm{C}$ NMR (DMSO- $d_{6}: \mathrm{CDCl}_{3} \approx 1: 6$ ): $\delta=20.32$ (C13); 117.46 (C7); 120.37 (C4); 123.03 (C2); 126.03 (C10); 128.84 (C11); 134.32 (C9); 136.08 (C3); 138.23 (C8); 148.09 (C1); 148.938 (C12); 154.84(C6); 155.01(C5).

HRMS $\left(\mathrm{C}_{22} \mathrm{H}_{17} \mathrm{~N}_{3}\right)$ : calc.: 323.3997 , found: 323.1422 .

MS $\left(70 \mathrm{eV}, \mathrm{El}, 150^{\circ} \mathrm{C}\right): 323.2\left(100[\mathrm{M}]^{+}\right), 308.2\left(6\left[\mathrm{M}-\mathrm{CH}_{3}\right]^{+}\right), 245.2\left(14\left[\mathrm{M}^{-} \mathrm{C}_{5} \mathrm{NH}_{4}\right]^{+}\right)$, $161.6\left(5.9[\mathrm{M}]^{2+}\right)$.

\section{4'-p-Bromomethylphenyl-2,2':6', 2'-terpyridine 7 [16]}

In a $50 \mathrm{~mL}$ reaction flask, 2,6-bis(2'-pyridyl)-4-p-tolylpyridine $(2.67 \mathrm{~g}, 0.0083 \mathrm{~mol})$, NBS $(1.78 \mathrm{~g}, 0.01 \mathrm{~mol})$ and 2,2'-azoisobutyronitrile $(0.1 \mathrm{~g})$ was refluxed in $\mathrm{CCl}_{4}(40$ $\mathrm{mL}$ ) under exposure of light for $6 \mathrm{~h}$. The hot reaction mixture was filtered, and the obtained solution was concentrated down to dryness. The bright yellow solid was recrystallized from a mixture of ethanol and acetone $(40 \mathrm{~mL}, 2: 1)$. The formed crystals were dried in vacuum. The yield was $1.71 \mathrm{~g}(0.00425 \mathrm{~mol}, 55 \%)$; m.p.: $151^{\circ} \mathrm{C}$ (lit.: $\left.162^{\circ} \mathrm{C}\right)$ ).

${ }^{1} \mathrm{H}$ NMR $\left(\mathrm{CDCl}_{3}\right): \delta=4.57(\mathrm{~s}, 2 \mathrm{H}, \mathrm{H} 13) ; 7.46(\mathrm{dd}, 2 \mathrm{H}, \mathrm{H} 2) ; 7.55(\mathrm{~d}, 2 \mathrm{H}, \mathrm{H} 11) ; 7.88$ (m, 4H, H3, H10); 8.79 (m, 4H, H1, H4); 8.83 (s, 2H,H7).

${ }^{1} \mathrm{H}$ NMR (DMSO- $\left.d_{6}: \mathrm{CDCl}_{3} \approx 1: 6\right): \delta=4.57(\mathrm{~s}, 2 \mathrm{H}, \mathrm{H} 13$ ); $7.36(\mathrm{dt}, 2 \mathrm{H}, \mathrm{H} 2) ; 7.53(\mathrm{~d}$, $2 \mathrm{H}, \mathrm{H} 11$ ); 7.85 (d, 2H, H10); 7.88 (dt, 2H, H3); 8.63 (d, 2H, H4); 8.69 (s, 2H, H7); $8.71(\mathrm{~d}, 2 \mathrm{H}, \mathrm{H} 1)$.

${ }^{13} \mathrm{C} \mathrm{NMR}\left(\mathrm{CDCl}_{3}\right): \delta=32.98$ (C13); 118.78 (C7); 121.36 (C4); 123.89 (C2); 127.75 (C10); 129.62 (C11); 136.91 (C3); 138.56 (C9, C8); 149.11 (C1); 149.48 (C12); 156.07, 155.96 (C5, C6).

${ }^{13} \mathrm{C}$ NMR (DMSO- $d_{6}: \mathrm{CDCl}_{3} \approx 1: 6$ ): $\delta=32.36$ (C13); 117.87 (C7); 120.59 (C4); 123.31 (C2); 126.84 (C10); 129.03 (C11); 136.30 (C3); 137.61 (C9); 138.05 (C8); 148.33 (C1); 148.49(C12); 155.04(C6); 155.17 (C5).

HRMS $\left(\mathrm{C}_{22} \mathrm{H}_{16} \mathrm{~N}_{3} \mathrm{Br}\right)$ : calc.: 402.2958 , found: 401.0528 .

MS (70 eV, El, $\left.160^{\circ} \mathrm{C}\right): 322.2\left(100[\mathrm{M}]^{+}\right), 244.1\left(4\left[\mathrm{M}-\mathrm{C}_{5} \mathrm{NH}_{4}\right]^{+}\right), 161.1\left(9[\mathrm{M}]^{2+}\right)$.

\section{Cellulose ethers 2}

Under an atmosphere of nitrogen, cellulose triacetate $(1 \mathrm{~g}, 3.47$ mmol-eq.) was stirred for $1 \mathrm{~h}$ at $70^{\circ} \mathrm{C}$ in dry DMSO $(100 \mathrm{~mL})$. After cooling down to room temperature, powdered $\mathrm{NaOH}(5 \mathrm{~g}, 0.125$ mol, 12 eqiv. pro $\mathrm{OH}$ ) was added. After $1 \mathrm{~h}$ stirring at room temperature, a mixture of benzyl bromide and 4-p-bromomethylphenyl-2,2':6',2"-terpyridine $(0.083 \mathrm{~mol}$ in sum), dissolved in DMSO $(20 \mathrm{~mL})$, was added. The reaction mixture was stirred at room temperature for 8 days. Water (400 $\mathrm{mL}$ ) was slowly added, and the whole mixture was extracted several times using $\mathrm{CH}_{2} \mathrm{Cl}_{2}$. The combined organic layers were rotavaporated to a small volume, and the polymer was precipitated by adding methanol $(100 \mathrm{~mL})$. The solid was redissolved in $\mathrm{CH}_{2} \mathrm{Cl}_{2}$ and the polymer was re-precipitated by adding methanol. The solid was dried in vacuum $\left(\mathrm{P}_{2} \mathrm{O}_{5}\right)$. 


\section{Benzyl cellulose 6a}

${ }^{1} \mathrm{H} \mathrm{NMR}\left(\mathrm{CDCl}_{3}\right): \delta=3.08(\mathrm{~s}, \mathrm{H} 5) ; 3.27(\mathrm{~s}, \mathrm{H} 2) ; 3.36(\mathrm{~s}, \mathrm{H} 3) ; 3.64(\mathrm{br}, \mathrm{H} 6) ; 3.94(\mathrm{~s}$, H4); 4.26 (dd, H1'); 4.41 (s, H1); 4.64 (d, H1'); 5.08 (d, H1'); 7.29 - 7.05 (H3'-H5').

${ }^{13} \mathrm{C}$ NMR $\left(\mathrm{CD}_{2} \mathrm{Cl}_{2}\right): \delta=69.05$ (C6); $73.72\left(\mathrm{C}^{\prime}\right) ; 75.72\left(\mathrm{C}^{\prime}\right) ; 75.95$ (C5); 77.55 (C4); 82.75 (C2); 83.97 (C3); 103.35 (C1); 128.92 - 127.74 (C3'-C5'); 139.4 (C2'); 140.36 (C2').

\section{Terpyridine-containing cellulose ethers $\mathbf{6 b}$}

${ }^{1} \mathrm{H}$ NMR $\left(\mathrm{CDCl}_{3}\right): \delta=3.01(\mathrm{br}, \mathrm{H} 5) ; 3.6-3.2(\mathrm{br}, \mathrm{H} 2, \mathrm{H} 3, \mathrm{H} 6) ; 3.88(\mathrm{br}, \mathrm{s}, \mathrm{H} 4) ; 4.25$ (br, H1, H1', H1"); 4.62 (br, H1', H1"); 5.06 (br, H1', H1"); 7.2 (br, H3'-5', H11", H12"); 7.8 (br, H3", H4"); 8.63 (br, H7", H10", H13").

${ }^{13} \mathrm{C}$ NMR $\left(\mathrm{CDCl}_{3}\right): \delta=68.14(\mathrm{br}, \mathrm{C} 6) ; 75.04,72.85$ (s, C1, C1"); 77 (br, C4, C5); 81.94 (s, C2); 83.26 (s, C3); 102.54 (s, C1); 118.78 (s, C7"); 121.34 (s, C10"); 123.79 (s, C12"); 127.79 (br, C3'-5', C3", C4"); 136.86 (s, C11"); 139.38, 138.42 (s, C2', C2"); 149.10 (s, C13"); 149.97 (s, C5", C6"); 156.24, 155.93 (s, C8", C9").

\section{Introduction of ruthenium(II) complexes}

$\mathrm{RuCl}_{3}(0.67 \mathrm{~g}, 0.0022 \mathrm{~mol})$ and 2,2':2",6'-terpyridine $(0.51 \mathrm{~g}, 0.0022 \mathrm{~mol})$ were refluxed for $3 \mathrm{~h}$ in dry ethanol $(130 \mathrm{~mL})$ under an atmosphere of nitrogen. After cooling down to room temperature, the dark brown solid was filtered of and washed successively with ethanol and water. After drying, the formed complex $\left[\mathrm{Ru}(\mathrm{tpy}) \mathrm{Cl}_{3}\right]$ was activated by refluxing for $2 \mathrm{~h}$ in a mixture of $\mathrm{AgBF}_{4}(1.3 \mathrm{~g}, 0.00667 \mathrm{~mol})$ and acetone $(30 \mathrm{~mL})$. After cooling down to room temperature, the mixture was filtered and concentrated down in vacuum. The reddish-violet residue was dissolved in 1-butanol $(20 \mathrm{~mL})$ and added slowly to a solution of terpyridine-substituted cellulose $(0.4 \mathrm{~g})$ in DMAc $(50 \mathrm{~mL})$ and 1-butanol $(40 \mathrm{~mL})$. At $70^{\circ} \mathrm{C}$, the mixture was stirred for $24 \mathrm{~h}$. The product was precipitated in a saturated aqueous $\mathrm{NaCl}$ solution $(200 \mathrm{~mL})$. The formed polymer was dried.

Acknowledgement: The authors wish to thank Deutsche Forschungsgemeinschaft (DFG) and Fonds der Chemischen Industrie (FCl) for financial support.

[1] (a) Klemm, D.; Philipp, B.; Heinze, T.; Heinze, U.; Wagenknecht, W.; "Comprehensive Cellulose Chemistry", vol. 1: 'Fundamentals and Analytical Methods', Wiley-VCH, Weinheim 1998. (b) Klemm, D.; Philipp, B.; Heinze, T.; Heinze, U.; Wagenknecht, W.; "Comprehensive Cellulose Chemistry", vol. 2: 'Functionalization of Cellulose', Wiley-VCH, Weinheim 1998.

[2] "Cellulose Derivatives - Modification, Characterization, and Nanostructures", Heinze, T.; Glaser W.; editors; ACS Symp. Ser. 688, 1998.

[3] Schmidt, B.; Bioforum 2000, 1, 19.

[4] Ruck, H.; Das Papier 1986, 40, 93, 153.

[5] Desai, N. B.; Wisotzki, K.; Seifen-Öle-Fette-Wachse 1991, 117, 124.

[6] Burchard, W., editor; "Polysaccharide", Springer, Berlin 1985. 
[7] Kondo, T.; J. Polym. Sci. 1994, B32, 1229.

[8] Brandt, L.; in 'Ullmann's Encyclopedia of Industrial Chemistry', Gerhartz, W., editor; $5^{\text {th }}$ edition, vol. $A 5, \mathrm{VCH}$, Weinheim 1986.

[9] Dönges, R.; Das Papier 1997, 51, 653.

[10] Löscher, F.; Ruckstuhl, T.; Jaworek, T.; Wegner, G.; Seeger, S.; Langmuir 1998, $14,2786$.

[11] Basque, P.; de Gunzbourg, A.; Rondeau, P.; Ritcey, A. M.; Langmuir 1996, 12, 5614.

[12] Fakirov, C.; Lieser, G.; Wegner, G.; Macromol. Chem. Phys. 1997, 198, 3407.

[13] Li, X. G.; Huang, M. R.; Hu, L.; Lin, G.; Yang, P. C.; Eur. Polym. J. 1999, 35, 157.

[14] Laube, B.; Radke, W.; Rehahn, M.; Wunderlich, W.; e-Polymers 2003, no. 66 (part 1 of this series).

[15] Schubert, U. S.; Eschbaumer, C.; Angew. Chem. 2002, 114, 3016.

[16] Spahni, W.; Calzaferri, G.; Helv. Chim. Acta 1984, 67, 450.

[17] Weiss, M.; J. Am. Chem. Soc. 1952, 74, 200.

[18] Collin, J. P.; Guillerez, S.; Sauvage, J.-P.; Barigelleti, F.; De Cola, L.; Flamigni, L.; Balzani, V.; Inorg. Chem. 1991, 36, 4230.

[19] Kröhnke, F.; Gross, F.; Chem. Ber. 1959, 92, 22.

[20] Kondo, T.; Gray, D. C.; J. Appl. Polym. Sci. 1992, 45, 417.

[21] Seufert, M.; Schaub, M.; Wenz, G.; Wegner, G.; Angew. Chem. 1995, 107, 363.

[22] Ashton, P. R.; Shibata, K.; Shipway, A. N.; Stoddart, J. F.; Angew. Chem. Int. Ed. Engl. 1997, 36, 2781. Zoltewicz, A.; Deady, K.; Heterocycl. Chem. 1978, 22, 71.

[23] Kelch, S.; Rehahn, M.; Macromolecules 1999, 32, 5818.

[24] Korall, P.; Börje, A.; Norrby, P. O.; Åkermark, B.; Acta Chim. Scan. 1997, 51, 760. 